Article

\title{
Buzzing Homes: Using Citizen Science Data to Explore the Effects of Urbanization on Indoor Mosquito Communities
}

\author{
Nadja Pernat ${ }^{1,2,3, *(\mathbb{D})}$, Helge Kampen ${ }^{4}$, Jonathan M. Jeschke ${ }^{2,3,5}$ and Doreen Werner ${ }^{1,3}$ \\ 1 Leibniz Centre for Agricultural Landscape Research, Eberswalder Str. 84, 15374 Müncheberg, Germany; \\ doreen.werner@zalf.de \\ 2 Institute of Biology, Freie Universität Berlin, Königin-Luise-Str. 1-3, 14195 Berlin, Germany; \\ jonathan.jeschke@fu-berlin.de \\ 3 Berlin-Brandenburg Institute of Advanced Biodiversity Research, Königin-Luise-Str. 2-4, \\ 14195 Berlin, Germany \\ 4 Friedrich-Loeffler-Institut, Federal Research Institute for Animal Health, Südufer 10, \\ 17493 Greifswald-Insel Riems, Germany; helge.kampen@fli.de \\ 5 Leibniz Institute of Freshwater Ecology and Inland Fisheries, Müggelseedamm 310, 12587 Berlin, Germany \\ * Correspondence: nadja.pernat@zalf.de
}

check for

updates

Citation: Pernat, N.; Kampen, H.; Jeschke, J.M.; Werner, D. Buzzing

Homes: Using Citizen Science Data to

Explore the Effects of Urbanization on Indoor Mosquito Communities.

Insects 2021, 12, 374. https://doi.org/ 10.3390 /insects 12050374

Academic Editors:

Cristina Castracani and

Alessandro Campanaro

Received: 26 February 2021

Accepted: 19 April 2021

Published: 21 April 2021

Publisher's Note: MDPI stays neutral with regard to jurisdictional claims in published maps and institutional affiliations.

Copyright: (C) 2021 by the authors Licensee MDPI, Basel, Switzerland. This article is an open access article distributed under the terms and conditions of the Creative Commons Attribution (CC BY) license (https:/ / creativecommons.org/licenses/by/ $4.0 /)$.
Simple Summary: Many mosquito species can transmit pathogens and may pose a risk to human health. With increasing urbanization and alteration of natural habitats, the composition of mosquito communities is changing, with some species thriving particularly well in and adjacent to human settlements. In the present study, indoor mosquito collections submitted to the citizen science project 'Mückenatlas' were used to investigate the composition, abundance, and diversity of species of different urbanization levels, and to detect preferences for less or more urbanized areas. We found that species richness and diversity decreases with increasing urbanization, and some important vector species are captured most frequently in densely urbanized regions. Our results highlight the importance of long-term mosquito monitoring to learn how these vectors respond to habitat change caused by humans. Only with sufficient knowledge about the ecology of mosquitoes can we assess risks, plan counter strategies, and take action.

Abstract: Urbanization has been associated with a loss of overall biodiversity and a simultaneous increase in the abundance of a few species that thrive in urban habitats, such as highly adaptable mosquito vectors. To better understand how mosquito communities differ between levels of urbanization, we analyzed mosquito samples from inside private homes submitted to the citizen science project 'Mückenatlas'. Applying two urbanization indicators based on soil sealing and human population density, we compared species composition and diversity at, and preferences towards, different urbanization levels. Species composition between groups of lowest and highest levels of urbanization differed significantly, which was presumably caused by reduced species richness and the dominance of synanthropic mosquito species in urban areas. The genus Anopheles was frequently submitted from areas with a low degree of urbanization, Aedes with a moderate degree, and Culex and Culiseta with a high degree of urbanization. Making use of citizen science data, this first study of indoor mosquito diversity in Germany demonstrated a simplification of communities with increasing urbanization. The dominance of vector-competent species in urban areas poses a potential risk of epidemics of mosquito-borne diseases that can only be contained by a permanent monitoring of mosquitoes and by acquiring a deeper knowledge about how anthropogenic activities affect vector ecology.

Keywords: biodiversity; citizen science; epidemiology; mosquitoes; urbanization

\section{Introduction}

With continuing outbreaks of mosquito-borne diseases in Mediterranean countries and recent cases of West Nile fever as far north as Germany, the management of mosquito 
vector species has become an important political and scientific issue throughout Europe [1]. Many countries have implemented mosquito-monitoring programs based on various methodological approaches. The collected data are used to update and predict species distributions, such as tracking the spread of invasive or native mosquito species that are capable of transmitting disease agents such as dengue, chikungunya, West Nile, or Zika viruses $[2,3]$.

Urbanization is thought to be one of the main anthropogenic drivers of changes in mosquito species composition and relative abundance through loss of natural larval habitats and the creation of new artificial ones [4-6]. With urbanization, an increase in population densities of those mosquito species is expected because they thrive in urban environments and in the vicinity of humans due to a selective advantage, e.g., the capability of breeding in artificial containers or the preference for human blood hosts. These include species of the genera Aedes, Anopheles, and Culex, some of which have invasive potential and can transmit a variety of pathogens, such as the Asian tiger mosquito Aedes albopictus [7]. Invasive species are highly adaptable and often prosper in urban environments, amplifying the risk of mosquito-borne disease outbreaks [8]. Consequently, it is of utmost interest and importance for risk assessment and epidemiological modelling to know which mosquito species dwell in human settlements and how mosquito communities differ based on surrounding environmental features such as the level and structure of urbanization.

Few studies about mosquito diversity in urban regions of Europe exist, with only two pertaining to metropolitan areas in Germany $[9,10]$ and only a handful for other European countries [11-16]. By comparison, responses of mosquito communities to urbanization have been investigated more intensively in North and South America [17,18], Asia [19,20], Australia [21], and Africa [22], probably due to past or recent outbreaks of mosquito-borne diseases. The majority of these investigations focus on identifying hotspots of one or two synanthropic, highly vector-competent species such as the yellow fever mosquito Aedes aegypti or Ae. albopictus in relation to urbanization [12,23]. Studies have rarely been aimed at capturing the entire mosquito biodiversity and relating it to urbanization [17]. A key reason for this lack of studies is that access to private properties is limited. The alternative-placing traps on public land-is risky and too often results in damaged or stolen devices [24]. As a result, it is deemed necessary to include residents in the research process via a citizen science approach in order to safely collect data from around and inside homes.

Citizen science has become an increasingly common form of research over the last decade [25-27]. Among its many benefits for society, it facilitates data collection on a spatial and temporal scale that scientists alone are barely able to cover [28]. However, there are doubts about the explanatory power of data gathered by non-professionals, as they tend to contain observation biases such as uneven spatial coverage [29-31], inconsistent sampling behavior [32,33], or uncertainties in object identification by the participants [34]. On the other hand, advanced methods have been developed in recent years for each stage of the scientific process, including avoidance of bias through adapted protocols $[35,36]$, verification of data using artificial intelligence [34,37,38], detection and statistical compensation of biases [33,39-42], and data integration [43].

Regarding urban ecology, data collected by citizens have been used in many studies, such as investigating the biodiversity of taxa like birds [44] or phorid flies [45], tracking invasive species [46], or initiating conservation action [47]. Many citizen science projects are aimed at monitoring and controlling mosquitoes as they are easily identifiable and people are personally concerned due to health implications or nuisance. In Italy, for example, a novel approach by Caputo et al. [48] used citizen surveys via an app (ZanzaMapp) to estimate mosquito abundance and nuisance. By means of the originally Spanish 'Mosquito Alert' smartphone app, participants could upload pictures of five important mosquito vectors and corresponding breeding habitats to inform health authorities in the Barcelona region [49] — a successful concept that has been launched in 17 other countries in 2020. Despite the relevance for public health, there is, to our knowledge, no study that explicitly 
focuses on the indoor biodiversity of mosquitoes. Indeed, very few studies have been conducted that target the insides of the participants' residences, although investigating the ecology and evolution of the indoor biome is an emerging research field and is predestined for citizen science approaches [50].

The lack of knowledge about which mosquitoes actually enter human residences might be partly filled by data from the citizen science project 'Mückenatlas', an implemented part of the German mosquito monitoring program. To gain knowledge about the occurrence and distribution of native and invasive mosquito species, this program was initiated in 2011 and consists of several monitoring schemes such as collecting eggs by ovitrapping, larvae by dipping, and adults by placing attractant traps. This systematic approach was extended by the passive surveillance instrument 'Mückenatlas' in 2012, where people were asked to collect and submit mosquito samples without any protocol and training [51]. By 2020, approximately 154,000, mostly hand-caught, mosquitoes had been submitted as physical samples, with more than $66 \%$ coming from the inside of the participants' homes, thus providing a rich data source for the current study.

This study investigates the indoor diversity of mosquitoes based on 'Mückenatlas' submissions from inside private homes. We take a multi-level approach to determine and specify differences of mosquito communities from varying levels of urbanization, defined by two indicator variables, soil sealing (surface imperviousness) and human population density. First, we visualize and test whether mosquito communities differ among levels of urbanization. Second, rarefied species richness and effective Shannon diversity as biodiversity indices are calculated to find explanations for the found differences. Finally, we investigate whether mosquitoes, aggregated into genera, show preferences for certain levels of urbanization. In the broader context of the uniqueness of the dataset, we simultaneously investigate whether the information contained in the data confirms our knowledge of mosquito ecology or even leads to new insights.

\section{Materials and Methods}

\subsection{The Citizen Science Dataset}

The 'Mückenatlas' project calls upon the German population to catch mosquitoes, kill them without damage, e.g., by freezing, and send them together with a submission form that is downloadable from the project website (www.mueckenatlas.com) to the involved institutes. Every participant is rewarded with a personal email or letter with details about the catch and, if desired, an individual marking on the collectors' map on the project website. The institutes will morphologically and, if necessary (i.e., in ambiguous cases), genetically identify the submitted sample to species level using the identification keys of Becker et al. [52] and Schaffner et al. [53] and CO1 barcoding [54], respectively. We considered mosquito groups or complexes (e.g., Anopheles maculipennis complex, Culex pipiens complex, Aedes annulipes group) as single taxa to account for impossibilities or uncertainties in differentiating females between species. These complexes or groups are referred to as species for simplification (Supplementary Materials Table S1). All data corresponding to a mosquito submission is uploaded to the German mosquito database CULBASE.

Data were extracted from CULBASE for the years 2012 to 2019. The dataset consisted of 26,060 entries, with each entry representing one mosquito species submission from one location on a unique date, hereafter referred to as submission. One submission might contain several individuals of the same species when participants caught more than one mosquito on the same occasion; these are then summed up in an additional count variable. The exported dataset comes with an automatically generated suite of covariates, such as geo-coordinates, land-use type, and collection date. In addition, the dataset has a variable that reflects the participants' comments on the collection location, such as garden, house, or stable etc. These were categorized manually, and all entries were then filtered according to the locations of the submissions from the interior, resulting in 16,933 observations. 


\subsection{Classification of Urbanization Level by Indicator Variables}

To define the corresponding level of urbanization of every observation, we used two indicator variables: (1) percentage of sealed soil (imperviousness) and (2) population density as the number of individuals per square kilometer. Concerning sealing, we basically followed the categorization by Böcker [55] and defined a value from 0 to $50 \%$ as low, from 51 to $70 \%$ as moderate, from 71 to $90 \%$ as strong, and from 91 to $100 \%$ as very strong. A grid of the percentage of soil sealing related to the surface of Germany with a resolution of one square kilometer served as the data base [56], from which the corresponding value was extracted for each individual submission location and then allocated to either low, moderate, strong, or very strong sealing. In addition to soil sealing as a common measure for urbanization, human population density was considered because humans unknowingly create numerous larval habitats, e.g., in private gardens, green spaces, or cemeteries, while also providing reliable sources of blood meals, either by themselves or by their pets and their livestock. The assessment according to human population density was derived from the degree of urbanization classification (DEGURBA) of the EU [57], categorizing a population density of up to 300 inhabitants per square kilometer as rural, between 300 and 5000 inhabitants per square kilometer as peri-urban, and above 5000 inhabitants per square kilometre as urban. We created a human population raster with square kilometer grid cells based on data from the German census in 2011 [58], extracted the corresponding data for every submission-related collection site, and assigned categories of either rural, peri-urban, or urban (see Supplementary Materials, Figure S1, for maps on distribution of both indicator variables across Germany). For simplification, we further refer to mosquito communities by level of urbanization as groups. Data preparation and creation of spatial covariates were conducted in $\mathrm{R}$ version 3.6.3 [59] with packages dplyr [60], raster [61], and rgdal [62].

\subsection{Statistical Analysis}

We used non-metric multidimensional scaling (NMDS) to explore differences in mosquito community composition according to level of urbanization, a common approach to visualize multidimensional data in two-dimensional space. This ordination technique is based on ranked proximities between the subjects of interests, in this case, the abundance (submission numbers) of mosquito species and level of urbanization. Each year of data collection (2012 to 2019) was treated as a replicated sample, and the respective urbanization levels of both indicators represented the sampling units. The impact of frequently submitted species was minimized by Wisconsin double standardization and square-root transformation, and the Bray-Curtis index was used to create dissimilarity matrices based on the species submission numbers within each group. For both runs with command metaMDS (vegan package), we calculated the stress level, which is an indicator of the reliability of the result, e.g., an ordination with a stress greater than 0.3 could also have occurred arbitrarily. To test the groups for statistically significant differences in species communities, a permutational multivariate analysis of variance (PERMANOVA) was applied, followed by a pairwise comparison of groups with a permutation test based on t-statistics (homogeneity of dispersion, PERMDISP).

We chose two biological diversity metrics, rarefied species richness, and effective Shannon diversity, which are robust against varying sample sizes and abundances, and facilitate comparing differences in biodiversity between groups. Rarefaction is a standardization technique that suits the 'Mückenatlas' data as it accounts for the different sample sizes and allows a fair comparison between the urbanization categories. For all calculations, we used the smallest sample size for each urbanization level in each year as the number of sub-samples randomly drawn from the larger samples to estimate expected species richness (sample-based rarefaction [63] with command rarefy of the vegan package).

The original Shannon-Wiener index was not used, as it is difficult to interpret and not robust against differences in abundances; in our case, number of submissions and sample sizes. These disadvantages are partially resolved by using the exponential of the 
Shannon-Wiener index to convert it to effective Shannon diversity. It indicates the effective number of species, i.e., those that are equally common, and allows us to directly compare the results among groups [64]. Following the calculation of rarefied species richness and effective Shannon diversity, we applied ANOVA for group-wise and post-hoc Student's $\mathrm{t}$-test with the Bonferroni-Holm adjustment for pairwise comparisons.

To find out whether the citizen science data can be used to infer preferences of mosquito genera for a certain level of urbanization, a Chi-square test of homogeneity was applied. Because the number of submissions from the considered level of urbanization varied greatly, we adapted the method of Bates et al. [65] by using weighted expected counts in the Chi-square test, i.e., we calculated for each of the five genera the summed ratio of the other four genera's observations from the different levels of urbanization to approximate the corresponding sampling effort in the expected count for the target genus. To test the single genera for significant tendencies of being submitted from certain levels of urbanization, the Chi-square residuals were computed and positive and negative tendencies visualized. These analyses were performed with $\mathrm{R}$ packages dplyr [60], vegan [66], ggpubr [67], and ggplot2 [68].

We opted for statistical analyses that allowed us to investigate how mosquito communities change along an urbanization gradient. For this purpose, we used species abundances for NMDS and biodiversity indices as well as abundances of genera for the Chi-square tests. A more detailed ecological examination of the occurrences of individual species, their habitat preferences, and contributions to differences in mosquito communities are beyond the scope of the current study and will be carried out in the future.

\section{Results}

Distribution of submissions over years and urbanization levels varied greatly (Figure 1 and Supplementary Materials, Table S2). Most submissions were recorded in 2016 and 2017, a phenomenon based on media topicality and recorder bias that has already been investigated in previous studies $[30,69]$. In general, a higher number of submissions came from lower to medium levels of urbanization than from very densely populated areas. The uneven distribution across the groups according to population density (inhabitants per square $\mathrm{km}$ ) is striking, with over two thirds of the entries coming from grid cells with 300 to 5000 inhabitants, which is not representative of the latest share of DEGURBA classes in Germany (34\% rural, $42 \%$ peri-urban, $24 \%$ urban [57]).

(a)

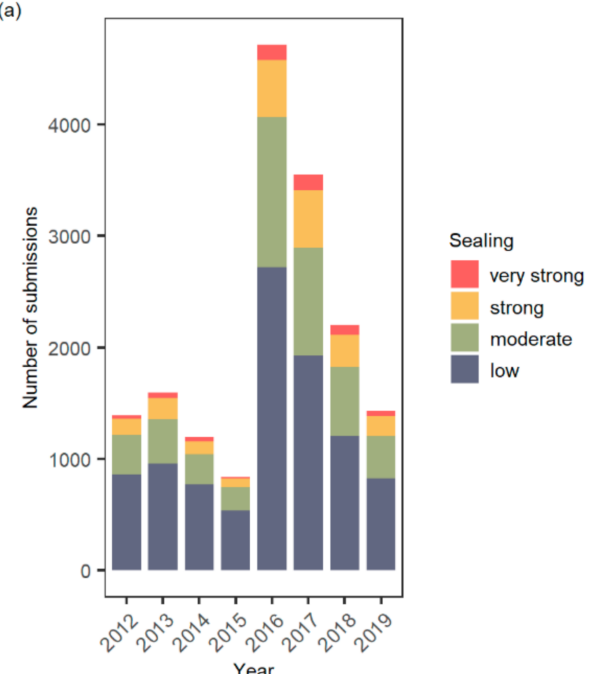

(b)

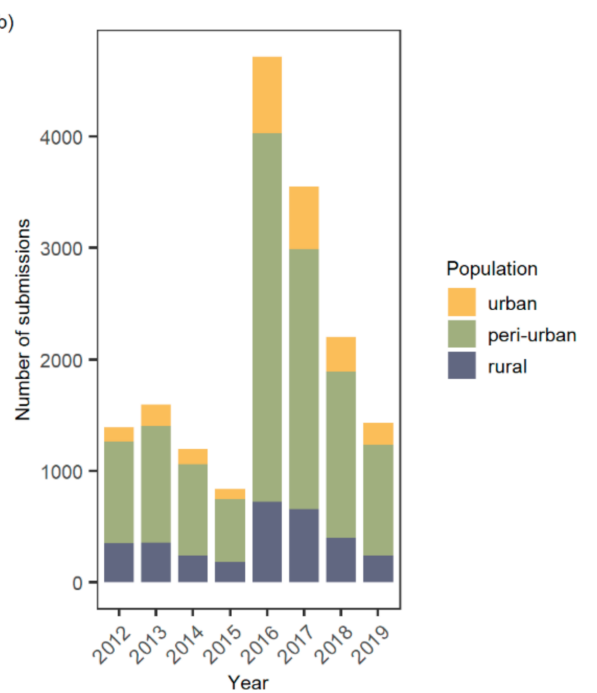

Figure 1. Numbers of submissions by year and level of urbanization, the latter assessed by (a) soil sealing and (b) human population density. 
The NMDS plots show differences in yearly mosquito assemblages by groups for both indicators of soil sealing (stress value $=0.14, \mathrm{R}^{2}=0.98$ ) and human population density (stress value $=0.14, \mathrm{R}^{2}=0.98$ ). Stress values indicate a fairly good fit (Figure 2). Visually, the NMDS plots (Figure 2) suggest that mosquito communities of high and low urbanized areas are distinct. The PERMANOVA is significant, and the variance explained is fair for both indicator variables of soil sealing $\left(\mathrm{R}^{2}=0.55, p<0.001\right)$ and human population density $\left(\mathrm{R}^{2}=0.44, p<0.001\right)$ (Supplementary Materials, Table S3, $p$-values based on permutations).
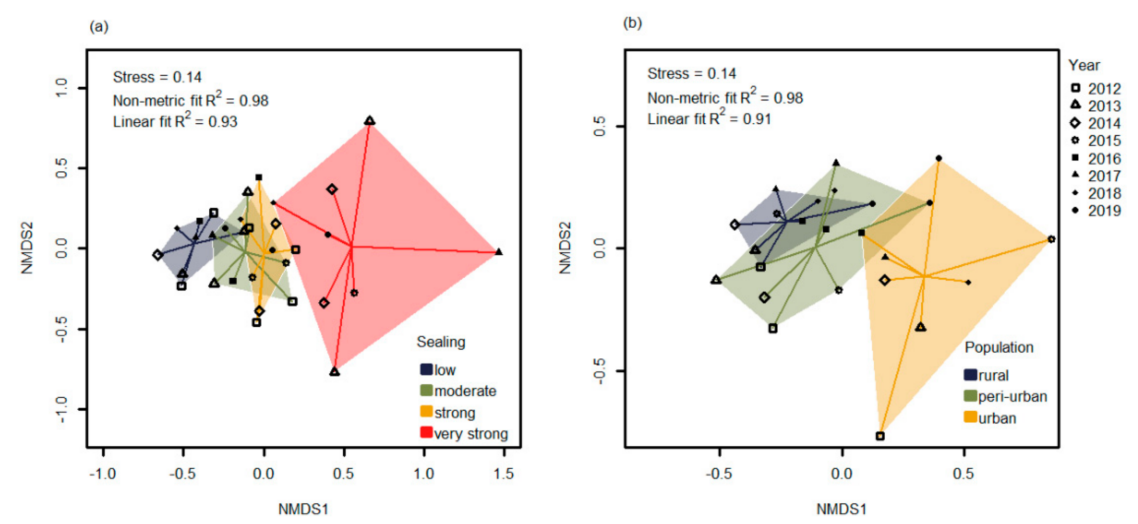

Figure 2. Non-metric multidimensional scaling (NMDS) showing differences in mosquito species communities of different levels of urbanization assessed by (a) soil sealing and (b) human population density, using years as replicates (symbols).

This result might indicate that there are different species present (or present in different abundances), depending on urbanization level. Significant PERMDISP for indicator soil sealing suggests that, for this variable, the difference might rather be due to within-group dispersion, e.g., of greater abundance variation in the group of low sealing than in the groups of strong and very strong sealing. The case was different for the indicator human population density, where the PERMDISP test was not significant. To better understand these patterns, biodiversity indices were calculated.

To explore the characteristics of the data, we plotted species richness, rarefied species richness, adjusted species richness, the Shannon-Wiener index, effective Shannon diversity, and the adjusted Shannon-Wiener index by year (Supplementary Materials, Figure S2). We then computed and visualized rarefied species richness and effective Shannon diversity per urbanization group and indicator (Figure 3). According to the ANOVA, rarefied species richness is not significantly different among groups for both indicator variables, i.e., the level of urbanization does not appear to have any influence on the number of species submitted when accounting for different sample sizes. With respect to effective Shannon diversity, we found significant differences between low and strong levels of urbanization. With a higher level of urbanization, the number of effective species decreases, i.e., there is a strong dominance of a few species (Cx. pipiens complex, Culiseta annulata and Aedes japonicus) in urban areas (Figure 3).

The omnibus Chi-square test revealed significant differences in the number of genera submitted per group for both indicators, soil sealing $\left(\chi^{2}=80.5, p<0.001\right)$ and human population density $\left(\chi^{2}=159.91, p<0.001\right)$. A follow-up with single comparisons (row-wise by genera to find out tendencies for level of urbanization) showed significant differences in submission numbers for most genera, except for Culiseta, regarding the urbanization indicator soil sealing, and Coquillettidia, regarding the indicator human population density (Table 1). 
(a)

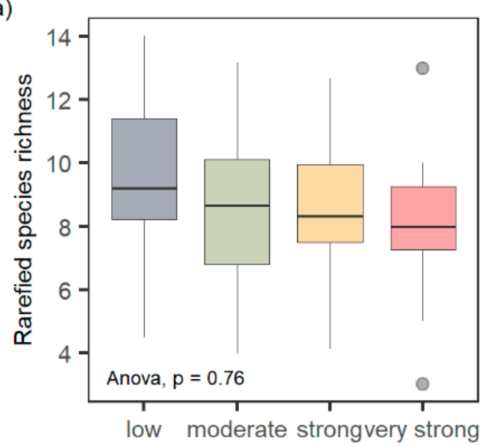

(c)

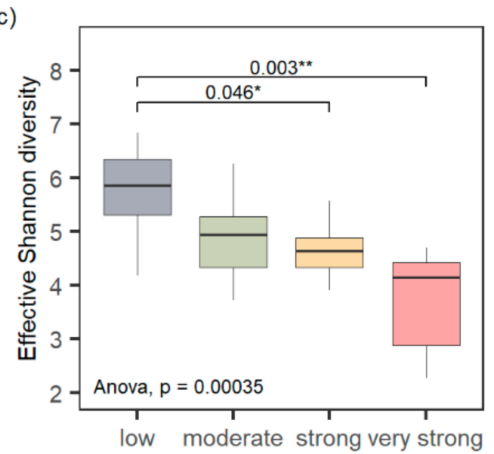

(b)

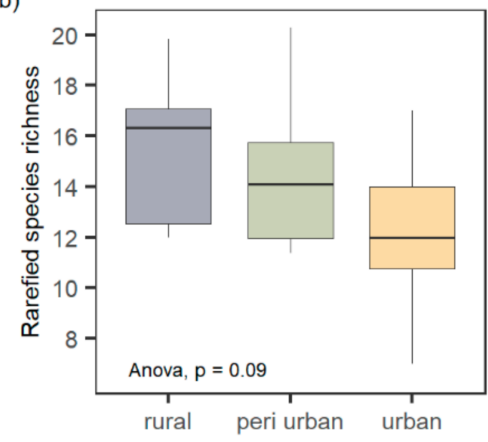

(d)

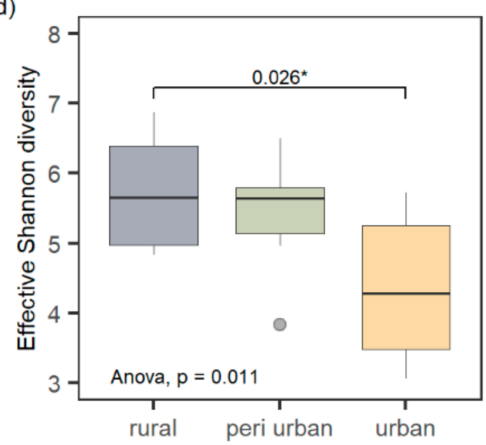

Figure 3. Boxplots comparing rarefied species richness, $(\mathbf{a}, \mathbf{b})$, and effective Shannon diversity (number of equally common species), (c,d), by urbanization level based on two indicators, soil sealing and human population density, using years as replicates. Thick black lines denote medians, first and third quartiles are shown by lower and upper hinges, and whiskers represent distance from hinge to the farthest value within the 1.5 interquartile range. Outliers are displayed individually. Symbols * and ${ }^{* *}$ indicate statistical significance at $\alpha<0.05$ and $<0.01$ based on $t$-tests with the Bonferroni-Holm correction (adjusted $p$-values displayed).

Table 1. Chi-square test of homogeneity for the number of observations per urbanization indicator-soil sealing and human population density - of five mosquito genera. Expected counts are weighted by the proportion of samples of the four other genera (ns = not significant).

\begin{tabular}{|c|c|c|c|c|c|c|c|c|c|c|}
\hline \multirow{2}{*}{$\begin{array}{c}\text { Genus } \\
\text { Sealing }\end{array}$} & \multicolumn{4}{|c|}{ Observed Counts } & \multicolumn{4}{|c|}{ Weighted Expected Counts } & \multirow[t]{2}{*}{$x^{2}$} & \multirow[t]{2}{*}{$p$-Value } \\
\hline & Low & Moderate & Strong & $\begin{array}{c}\text { Very } \\
\text { Strong }\end{array}$ & Low & Moderate & Strong & $\begin{array}{c}\text { Very } \\
\text { Strong }\end{array}$ & & \\
\hline Aedes & 2386 & 1064 & 427 & 86 & 2268 & 1063 & 489 & 143 & 36.61 & $<0.001$ \\
\hline Anopheles & 464 & 149 & 65 & 12 & 397 & 187 & 83 & 23 & 28.23 & $<0.001$ \\
\hline Coquillettidia & 238 & 79 & 31 & 12 & 208 & 97 & 43 & 12 & 11.21 & $<0.011$ \\
\hline Culex & 4424 & 2150 & 1023 & 300 & 4706 & 2092 & 877 & 222 & 70.40 & $<0.001$ \\
\hline Culiseta & 2297 & 1102 & 480 & 144 & 2341 & 1073 & 482 & 128 & 3.70 & ns \\
\hline Population & Rural & $\begin{array}{l}\text { Peri- } \\
\text { Urban }\end{array}$ & Urban & & Rural & $\begin{array}{l}\text { Peri- } \\
\text { Urban }\end{array}$ & Urban & & & \\
\hline Aedes & 645 & 2830 & 488 & & 738 & 2683 & 543 & & 4.18 & $<0.001$ \\
\hline Anopheles & 233 & 413 & 44 & & 128 & 467 & 94 & & 131.24 & $<0.001$ \\
\hline Coquillettidia & 80 & 239 & 41 & & 67 & 244 & 49 & & 41.81 & ns \\
\hline Culex & 1462 & 5311 & 1124 & & 1470 & 5346 & 1081 & & 71.62 & $<0.028$ \\
\hline Culiseta & 732 & 2670 & 621 & & 749 & 2723 & 551 & & 8.51 & $<0.001$ \\
\hline
\end{tabular}

By visualizing the Pearson residuals of the Chi-square test to explore tendencies of mosquito genera for a certain urbanization level (Figure 4), a general preference of the genus Anopheles for rural areas, of the genera Culex and Culiseta for more densely populated environments, and of the genus Aedes for peri-urban spaces could be demonstrated. 
(a)

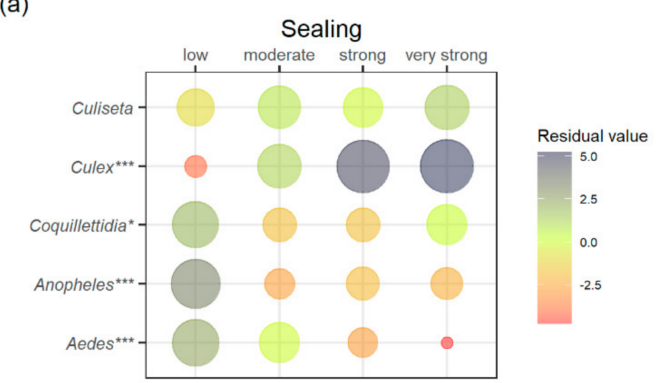

(b)

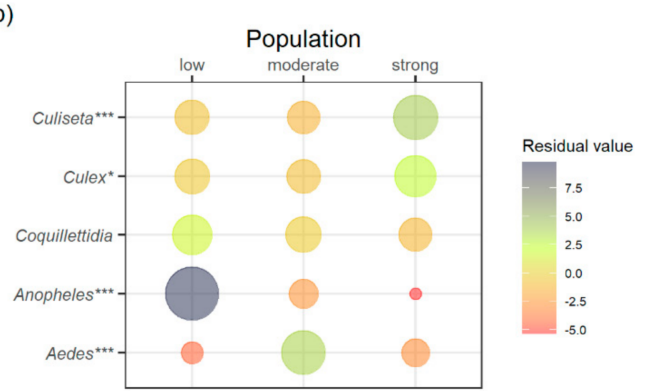

Figure 4. Tendencies of genera for a certain level of urbanization categorized by the indicators soil sealing (a) and human population density $(\mathbf{b})$ by means of Pearson residuals. Dot size corresponds to the overall contribution to the total Chi-square value. Positive scores indicate an attraction (green to blue) and negative scores indicate a repulsion between rows and columns (yellow to red). Significant differences from row-wise comparisons are indicated $\left.{ }^{*}=p<0.05,{ }^{* * *}=p<0.001\right)$.

\section{Discussion}

This is the first large-scale indoor mosquito biodiversity study for Germany, based on 16,933 submissions to the citizen science monitoring scheme 'Mückenatlas' from inside the homes of the participants between 2012 and 2019. Without the contribution of citizens, it would not have been possible to collect such data and analyze the biodiversity of mosquitoes in human housing. Therefore, citizen science seems almost a necessity for indoor biome research, at whatever scale. For example, at the lowest scale, citizens could participate simply by letting scientists into their homes so that professionals can systematically sample there (e.g., [70]). In this case, the involvement of citizens in the scientific process is extremely limited, as is the amount of data that is collected because this is highly dependent on financial and human resources. The scaling of projects can be expanded in time and space the more autonomously and flexibly citizens are involved, e.g., in physical data sampling, photorecording observations, or other parts of the scientific process [71].

However, while the flexibility of the protocol leads to a high number of participants, it also induces data bias [31]. In the case of the 'Mückenatlas' scheme, differences in sample size by urbanization level reflects a spatial bias, predominantly caused by population density, a phenomenon well-known from opportunistic citizen science data [29,30,33,72]. In this study, the huge differences in sample sizes within years and between the groups of urbanization level were counteracted with rather simple methods to demonstrate the general interpretability and usefulness of the opportunistic data collection for addressing ecological questions. Regardless of the biases that need to be addressed with methods according to the analysis objective, involving citizens might be the only way to get indoor biome data at all. Citizen science is also crucial for collecting a meaningful amount of information when it comes to national, continental, or even cross-continental comparative studies.

With the support of citizens providing valuable information from their homes, this study found that indoor mosquito communities differ by urbanization level. A location effect could be identified for the indicator human population density, whereas differences of the indicator soil sealing might be due to within-group dispersion, e.g., changes in relative abundances within the group over the years. By further applying biodiversity indices to shed more light on these differences, we see that the tendency that rarefied species richness decreases with increasing urbanization, as already demonstrated in smaller scale studies $[11,15,73]$. The higher species richness of sample aggregations stemming from rural homes appear to reflect a more heterogeneous landscape featuring habitats suitable for rarer and more specialized mosquito species. However, total species richness independent from level of urbanization varies greatly over time (Supplementary Materials, Figure S2), suggesting that fluctuating factors other than soil sealing and human population density shape the recordable diversity of species. Climatic conditions greatly influence the development and composition of mosquito communities [74-76] and can lead to higher 
densities, nuisance, and media topicality, thus increasing the probability of a submission by a 'Mückenatlas' participant [30]. In addition, the opportunistic data collection is not only biased by human population and climatic variability but also by taxonomic preferences [32] In the case of citizen science programs where both native and invasive taxa are of interest, people tend to look out for the intruders $[77,78]$. Therefore, species richness estimates from citizen science data need to be carefully interpreted and, if possible, combined or cross-checked with professional data $[79,80]$.

Comparison of effective Shannon diversity also indicates that diversity decreases with urbanization, thereby supporting the results of rarefied species richness estimates and partly explaining the significant difference of the groups. Although a meta-study by Fenoglio et al. [81] found hematophagues to be the only group of arthropods that generally seems to positively respond to urban environments, mosquito communities are less diverse in populated and sealed areas $[11,73,82]$. While the disturbance of natural habitats through deforestation or drainage of wetlands negatively affects the life cycle of rather specialized species, adaptive generalists are promoted by urbanization. Indeed, some of the most competent vectors of the Aedes, Culex, and Anopheles genera show tendencies to exploit edges of disturbance such as forest-arable land transitions, abandoned stables, or construction sites at urban expansion borders [21,83]. The tendency of submitted Aedes specimens to be collected predominantly in peri-urban areas could therefore also be due to high submission numbers of Ae. japonicus, a species that also prefers these transition zones, to the 'Mückenatlas' scheme [84].

Of all mosquito genera, Culex is the most frequent in urban and strongly sealed areas, mainly due to the high numbers of $C x$. pipiens complex submissions. Members of the $C x$. pipiens complex are ecologically and physiologically flexible and are known to thrive in urban areas $[85,86]$. They reproduce as easily as other urban-adapted mosquito species in widely available artificial containers [87]. As such, artificial containers offer microhabitats that enable mosquito species to survive despite dry seasons or droughts [88]. Even the emergence of the human-biting preference of Ae. aegypti or a shift of breeding site selection by the minor malaria vector, Anopheles plumbeus, towards man-made habitats can now be attributed to adaptation to urban regions with reliable water sources [88-90].

\section{Conclusions}

Our results demonstrate that citizen science is an appropriate method in the process of analyzing the indoor biome and, moreover, that the 'Mückenatlas' opportunistic data collection not only confirms existing knowledge but also enables completely new insights into urban mosquito ecology. Although the analysis is greatly simplified by combining all submissions and creating artificial groups of mosquito communities, regardless of the geographical or climatic conditions of the original location, the explanatory power of the data is strong - certainly due to the large observation number. Citizen science is therefore not only recommended for inclusion in formal mosquito monitoring programs to enlarge the data basis for better risk assessments and modelling, it could also unleash a truly invaluable resource that can significantly advance the global indoor biome data-the people at home [91].

The results of this study are also relevant for public health in Germany. The high submission numbers of $C x$. pipiens complex from within people's homes and from high levels of urbanization (i.e., densely populated areas) highlight the risk of human exposure to mosquito-borne disease in the country. The simplification of mosquito communities in urban areas worldwide, as confirmed by our study, is caused by less differentiation of breeding sites through homogenization of urban habitats, which is in turn linked to higher infection rates [11,73]. Initial natural diversity would not recover, even over a century after being urbanized [17], so the natural mechanism of reducing species-related nuisance through intraspecific competition will not be restored. In the face of accelerated urbanization and global warming, precautions can only be taken with further intensive surveillance and knowledge acquisition. Therefore, continuous mosquito monitoring 
on large scales, even cross-national, with conventional methods and citizen science are just as essential as targeted small-scale field studies to achieve a better understanding of vector ecology.

Supplementary Materials: The following is available online at https:/ /www.mdpi.com/article/10 .3390 /insects12050374/s1, Table S1: Species list with corresponding numbers of submissions to the 'Mückenatlas'. Table S2: Total counts of submissions by year and level of urbanization; Table S3: PERMANOVA results based on Bray-Curtis dissimilarities using square-rooted abundance data for indoor mosquito communities grouped by (a) soil sealing and (b) human population density; Figure S1: Distribution of indicator categories across Germany; Figure S2: Differences in the biodiversity indices with or without consideration of the sampling effort across all years, regardless of urbanization indicator. Figures S1 and S2 were produced in R [59].

Author Contributions: Conceptualization, N.P.; methodology, N.P. and J.M.J.; software, N.P.; formal analysis, N.P.; writing-original draft preparation, N.P.; writing-review and editing, N.P., H.K., J.M.J., and D.W.; visualization, N.P.; supervision, H.K., J.M.J., and D.W.; project administration, H.K. and D.W.; funding acquisition, H.K. and D.W. All authors have read and agreed to the published version of the manuscript.

Funding: This research was funded by the German Federal Ministry of Food and Agriculture (BMEL) through the Federal Office for Agriculture and Food (BLE), grant numbers 2810HS022, 2819104615 , and 2818SE001. The publication of this article was funded by the Open Access Fund of the Leibniz Association.

Institutional Review Board Statement: Not applicable.

Data Availability Statement: For the time being, mosquito data used in the submitted manuscript cannot be provided publicly as it would violate the personal privacy of the citizen scientists.

Acknowledgments: We thank all 'Mückenatlas' project participants for their submissions. We are also grateful to the laboratory staff and the Ph.D. students of the Leibniz Centre for Agricultural Landscape Research, Müncheberg, Germany, and of the Friedrich-Loeffler-Institut, Greifswald, Germany, involved in the various monitoring projects, as well as to Stefan Kowalczyk, Institute of Epidemiology of the Friedrich-Loeffler-Institut, Greifswald, Germany, for database maintenance.

Conflicts of Interest: The authors declare no conflict of interest.

\section{References}

1. Gossner, C.M.; Ducheyne, E.; Schaffner, F. Increased risk for autochthonous vector-borne infections transmitted by Aedes albopictus in continental Europe. Eurosurveillance 2018, 23, 1-6. [CrossRef] [PubMed]

2. Medlock, J.M.; Hansford, K.M.; Versteirt, V.; Cull, B.; Kampen, H.; Fontenille, D.; Hendrickx, G.; Zeller, H.; Van Bortel, W.; Schaffner, F. An entomological review of invasive mosquitoes in Europe. Bull. Entomol. Res. 2015, 105, 637-663. [CrossRef] [PubMed]

3. Kampen, H.; Walther, D. Vector potential of mosquito species (Diptera: Culicidae) occurring in Central Europe. In Mosquito-Borne Diseases: Implications for Public Health; Benelli, G., Mehlhorn, H., Eds.; Springer: Berlin/Heidelberg, Germany, 2018; Volume 10, pp. 41-68. [CrossRef]

4. Rochlin, I.; Faraji, A.; Ninivaggi, D.V.; Barker, C.M.; Kilpatrick, A.M. Anthropogenic impacts on mosquito populations in North America over the past century. Nat. Commun. 2016, 7, 13604. [CrossRef] [PubMed]

5. Norris, D.E. Mosquito-borne diseases as a consequence of land use change. EcoHealth 2004, 1, 19-24. [CrossRef]

6. Field, E.N.; Tokarz, R.E.; Smith, R.C. Satellite imaging and long-term mosquito surveillance implicate the influence of rapid urbanization on Culex vector populations. Insects 2019, 10, 269. [CrossRef]

7. Wilke, A.B.B.; Beier, J.C.; Benelli, G. Complexity of the relationship between global warming and urbanization-an obscure future for predicting increases in vector-borne infectious diseases. Curr. Opin. Insect Sci. 2019, 35, 1-9. [CrossRef]

8. Wilke, A.B.B.; Benelli, G.; Beier, J.C. Beyond frontiers: On invasive alien mosquito species in America and Europe. PLoS Negl. Trop. Dis. 2020, 14, e0007864. [CrossRef]

9. Kruger, A.; Borstler, J.; Badusche, M.; Luhken, R.; Garms, R.; Tannich, E. Mosquitoes (Diptera: Culicidae) of metropolitan Hamburg, Germany. Parasitol. Res. 2014, 113, 2907-2914. [CrossRef]

10. Honnen, A.C.; Monaghan, M.T.; Sharakhov, I. City-dwellers and country folks: Lack of population differentiation along an urban-rural gradient in the mosquito Culex pipiens (Diptera: Culicidae). J. Insect Sci. 2017, 17. [CrossRef]

11. Townroe, S.; Callaghan, A. British container breeding mosquitoes: The impact of urbanisation and climate change on community composition and phenology. PLoS ONE 2014, 9, e95325. [CrossRef] 
12. Manica, M.; Filipponi, F.; D'Alessandro, A.; Screti, A.; Neteler, M.; Rosa, R.; Solimini, A.; Della Torre, A.; Caputo, B. Spatial and temporal hot spots of Aedes albopictus abundance inside and outside a South European metropolitan area. PLoS Negl. Trop. Dis. 2016, 10, e0004758. [CrossRef]

13. Lebl, K.; Zittra, C.; Silbermayr, K.; Obwaller, A.; Berer, D.; Brugger, K.; Walter, M.; Pinior, B.; Fuehrer, H.P.; Rubel, F. Mosquitoes (Diptera: Culicidae) and their relevance as disease vectors in the city of Vienna, Austria. Parasitol. Res. 2015, 114, 707-713. [CrossRef]

14. Klobucar, A.; Benic, N.; Krajcar, D.; Kosanovic-Licina, M.L.; Tesic, V.; Merdic, E.; Vrucina, I.; Savic, V.; Barbic, L.; Stevanovic, V.; et al. An overview of mosquitoes and emerging arboviral infections in the Zagreb area, Croatia. J. Infect. Dev. Ctries. 2016, 10, 1286-1293. [CrossRef]

15. Ferraguti, M.; Martinez-de la Puente, J.; Roiz, D.; Ruiz, S.; Soriguer, R.; Figuerola, J. Effects of landscape anthropization on mosquito community composition and abundance. Sci. Rep. 2016, 6, 29002. [CrossRef]

16. Dzidová, M.; Čabanová, V.; Stloukal, E.; Miterpáková, M. Fluctuation of mosquito species in capital city of Slovakia in years 2015 and 2016. Folia Faun. Slov. 2016, 21, 245-250.

17. Spence Beaulieu, M.R.; Hopperstad, K.; Dunn, R.R.; Reiskind, M.H. Simplification of vector communities during suburban succession. PLoS ONE 2019, 14, e0215485. [CrossRef]

18. Cardo, M.V.; Rubio, A.; Junges, M.T.; Vezzani, D.; Carbajo, A.E. Heterogeneous distribution of Culex pipiens, Culex quinquefasciatus and their hybrids along the urbanisation gradient. Acta Trop. 2018, 178, 229-235. [CrossRef]

19. Thongsripong, P.; Green, A.; Kittayapong, P.; Kapan, D.; Wilcox, B.; Bennett, S. Mosquito vector diversity across habitats in central Thailand endemic for dengue and other arthropod-borne diseases. PLoS Negl. Trop. Dis. 2013, 7, e2507. [CrossRef]

20. Mogi, M.; Armbruster, P.A.; Tuno, N. Differences in responses to urbanization between invasive mosquitoes, Aedes japonicus japonicus (Diptera: Culicidae) and Aedes albopictus, in their native range, Japan. J. Med. Entomol. 2020, 57, 104-112. [CrossRef]

21. Meyer Steiger, D.B.; Ritchie, S.A.; Laurance, S.G. Mosquito communities and disease risk influenced by land use change and seasonality in the Australian tropics. Parasit. Vectors 2016, 9, 387. [CrossRef]

22. Mayi, M.P.A.; Bamou, R.; Djiappi-Tchamen, B.; Fontaine, A.; Jeffries, C.L.; Walker, T.; Antonio-Nkondjio, C.; Cornel, A.J.; Tchuinkam, T. Habitat and seasonality affect mosquito community composition in the west region of Cameroon. Insects 2020, 11, 312. [CrossRef]

23. Lopes, J.; Martins, E.A.C.; de Oliveira, O.; de Oliveira, V.; de Oliveira Neto, B.P.; de Oliveira, J.E. Dispersion of Aedes aegypti (Linnaeus, 1762) and Aedes albopictus (Skuse, 1894) in the rural zone of North Paraná state. Brazil. Arch. Biol. Technol. 2004, 47, 739-746. [CrossRef]

24. Müller, P.; Engeler, L.; Vavassori, L.; Suter, T.; Guidi, V.; Gschwind, M.; Tonolla, M.; Flacio, E. Surveillance of invasive Aedes mosquitoes along Swiss traffic axes reveals different dispersal modes for Aedes albopictus and Ae. japonicus. PLoS Negl. Trop. Dis. 2020, 14, e0008705. [CrossRef]

25. Kullenberg, C.; Kasperowski, D. What is citizen science? A scientometric meta-analysis. PLoS ONE 2016, 11, e0147152. [CrossRef]

26. Follett, R.; Strezov, V. An analysis of citizen science based research: Usage and publication patterns. PLoS ONE 2015, 10, e0143687. [CrossRef]

27. Bautista-Puig, N.; De Filippo, D.; Mauleón, E.; Sanz-Casado, E. Scientific landscape of citizen science publications: Dynamics, content and presence in social media. Publications 2019, 7, 12. [CrossRef]

28. Dickinson, J.L.; Zuckerberg, B.; Bonter, D.N. Citizen science as an ecological research tool: Challenges and benefits. Annu. Rev. Ecol. Evol. Syst. 2010, 41, 149-172. [CrossRef]

29. Tiago, P.; Ceia-Hasse, A.; Marques, T.A.; Capinha, C.; Pereira, H.M. Spatial distribution of citizen science casuistic observations for different taxonomic groups. Sci. Rep. 2017, 7, 12832. [CrossRef]

30. Pernat, N.; Kampen, H.; Ruland, F.; Jeschke, J.M.; Werner, D. Drivers of spatio-temporal variation in mosquito submissions to the citizen science project 'Mückenatlas'. Sci. Rep. 2021, 11, 1356. [CrossRef]

31. Geldmann, J.; Heilmann-Clausen, J.; Holm, T.E.; Levinsky, I.; Markussen, B.; Olsen, K.; Rahbek, C.; Tøttrup, A.P.; Leung, B. What determines spatial bias in citizen science? Exploring four recording schemes with different proficiency requirements. Divers. Distrib. 2016, 22, 1139-1149. [CrossRef]

32. Ward, D.F. Understanding sampling and taxonomic biases recorded by citizen scientists. J. Insect Conserv. 2014, 18, 753-756. [CrossRef]

33. Mair, L.; Ruete, A. Explaining spatial variation in the recording effort of citizen science data across multiple taxa. PLoS ONE 2016, 11, e0147796. [CrossRef] [PubMed]

34. Kelling, S.; Fink, D.; La Sorte, F.A.; Johnston, A.; Bruns, N.E.; Hochachka, W.M. Taking a 'Big Data' approach to data quality in a citizen science project. Ambio 2015, 44 (Suppl. 4), 601-611. [CrossRef] [PubMed]

35. Lewandowski, E.; Specht, H. Influence of volunteer and project characteristics on data quality of biological surveys. Conserv. Biol. 2015, 29, 713-723. [CrossRef]

36. Kelling, S.; Johnston, A.; Bonn, A.; Fink, D.; Ruiz-Gutierrez, V.; Bonney, R.; Fernandez, M.; Hochachka, W.M.; Julliard, R.; Kraemer, R.; et al. Using semistructured surveys to improve citizen science data for monitoring biodiversity. Bioscience 2019, 69, 170-179. [CrossRef]

37. Wäldchen, J.; Mäder, P.; Cooper, N. Machine learning for image based species identification. Methods Ecol. Evol. 2018, 9, 2216-2225. [CrossRef] 
38. Muñoz, J.P.; Boger, R.; Dexter, S.; Low, R. Mosquitoes and public health: Improving data validation of citizen science contributions using computer vision. In Delivering Superior Health and Wellness Management with IoT and Analytics. Healthcare Delivery in the Information Age; Wickramasinghe, N., Bodendorf, F., Eds.; Springer: Cham, Switzerland, 2020; Part 1; pp. $469-493$.

39. Bradter, U.; Mair, L.; Jönsson, M.; Knape, J.; Singer, A.; Snäll, T.; Anderson, B. Can opportunistically collected citizen science data fill a data gap for habitat suitability models of less common species? Methods Ecol. Evol. 2018, 9, 1667-1678. [CrossRef]

40. Henckel, L.; Bradter, U.; Jönsson, M.; Isaac, N.J.B.; Snäll, T.; Real, R. Assessing the usefulness of citizen science data for habitat suitability modelling: Opportunistic reporting versus sampling based on a systematic protocol. Divers. Distrib. 2020, 26, 1276-1290. [CrossRef]

41. Isaac, N.J.B.; van Strien, A.J.; August, T.A.; de Zeeuw, M.P.; Roy, D.B.; Anderson, B. Statistics for citizen science: Extracting signals of change from noisy ecological data. Methods Ecol. Evol. 2014, 5, 1052-1060. [CrossRef]

42. Johnston, A.; Moran, N.; Musgrove, A.; Fink, D.; Baillie, S.R. Estimating species distributions from spatially biased citizen science data. Ecol. Model. 2020, 422, 108927. [CrossRef]

43. Isaac, N.J.B.; Jarzyna, M.A.; Keil, P.; Dambly, L.I.; Boersch-Supan, P.H.; Browning, E.; Freeman, S.N.; Golding, N.; Guillera-Arroita, G.; Henrys, P.A.; et al. Data integration for large-scale models of species distributions. Trends Ecol. Evol. 2020, 35, 56-67. [CrossRef]

44. Callaghan, C.T.; Martin, J.M.; Major, R.E.; Kingsford, R.T. Avian monitoring-comparing structured and unstructured citizen science. Wildl. Res. 2018, 45, 176-184. [CrossRef]

45. Brown, B.V.; Hartop, E.A. Big data from tiny flies: Patterns revealed from over 42,000 phorid flies (Insecta: Diptera: Phoridae) collected over one year in Los Angeles, California, USA. Urban Ecosyst. 2016, 20, 521-534. [CrossRef]

46. Sladonja, B.; Poljuha, B. Citizen science as a tool in biological recording-A case study of Ailanthus altissima (Mill.) Swingle. Forests 2018, 9, 31. [CrossRef]

47. Spear, D.M.; Pauly, G.B.; Kaiser, K. Citizen science as a tool for augmenting museum collection data from urban areas. Front. Ecol. Evol. 2017, 5, 86. [CrossRef]

48. Caputo, B.; Manica, M.; Filipponi, F.; Blangiardo, M.; Cobre, P.; Delucchi, L.; De Marco, C.M.; Iesu, L.; Morano, P.; Petrella, V.; et al. ZanzaMapp: A scalable citizen science tool to monitor perception of mosquito abundance and nuisance in Italy and beyond. Int. J. Environ. Res. Public Health 2020, 17, 7872. [CrossRef]

49. Palmer, J.R.B.; Oltra, A.; Collantes, F.; Delgado, J.A.; Lucientes, J.; Delacour, S.; Bengoa, M.; Eritja, R.; Bartumeus, F. Citizen science provides a reliable and scalable tool to track disease-carrying mosquitoes. Nat. Commun. 2017, 8, 916. [CrossRef]

50. NESCent Working Group on the Evolutionary Biology of the Built Environment; Martin, L.J.; Adams, R.I.; Bateman, A.; Bik, H.M.; Hawks, J.; Hird, S.M.; Hughes, D.; Kembel, S.W.; Kinney, K.; et al. Evolution of the indoor biome. Trends Ecol. Evol. 2015, 30, 223-232. [CrossRef]

51. Walther, D.; Kampen, H. The citizen science project 'Mueckenatlas' helps monitor the distribution and spread of invasive mosquito species in Germany. J. Med. Entomol. 2017, 54, 1790-1794. [CrossRef]

52. Becker, N.; Petric, D.; Zgomba, M.; Boase, C.; Madon, M.B.; Dahl, C.; Kaiser, A. Mosquitoes and Their Control, 2nd ed.; Springer: Berlin/Heidelberg, Germany, 2010.

53. Schaffner, F.; Angel, G.; Geoffroy, B.; Hervy, J.; Rhaiem, A.; Brunhes, J. The Mosquitoes of Europe. An Identification and Training Programme (CD-Rom); IRD Éditions \& EID: Méditerrannée, Montpellier, France, 2001.

54. Heym, E.C.; Kampen, H.; Walther, D. Mosquito species composition and phenology (Diptera, Culicidae) in two German zoological gardens imply different risks of mosquito-borne pathogen transmission. J. Vector. Ecol. 2018, 43, 80-88. [CrossRef]

55. Böcker, R. Bodenversiegelung-Verlust vegetationsbedeckter Flächen in Ballungsräumen am Beispiel von Berlin (West). Landsch. Stadt 1985, 17, 57-61.

56. European Union. Copernicus Land Monitoring Service, European Environment Agency (EEA) (2012). Available online: https: / / land.copernicus.eu/ (accessed on 29 June 2020).

57. Dijkstra, L.; Poelmann, H. A Harmonised Definition of Cities and Rural Areas: The New Degree of Urbanisation. European Commission Urban and Re-gional Policy. Working Paper 1. 2014. Available online: https://ec.europa.eu/regional_policy/ sources/docgener/work/2014_01_new_urban.pdf (accessed on 26 June 2020).

58. Statistisches Bundesamt, Wiesbaden. 2015. Available online: https://ergebnisse.zensus2011.de/ (accessed on 28 February 2019).

59. R Core Team. R: A Language and Environment for Statistical Computing; R Foundation for Statistical Computing: Vienna, Austria, 2018.

60. Wickham, H.; Romain, F.; Henry, L.; Müller, K. dplyr: A Grammar of Data Manipulation. R Package Version 0.8.5. 2020. Available online: https: / CRAN.R-project.org/package=dplyr (accessed on 8 April 2021).

61. Hijmans, R.J. raster: Geographic Data Analysis and Modeling. R Package Version 2.8-19. 2019. Available online: https: / /CRAN.R-project.org / package=raster (accessed on 3 February 2021).

62. Bivand, R.; Keitt, T.; Rowlingson, B. rgdal: Bindings for the 'Geospatial' Data Abstraction Library. R Package Version 1.4-3. 2019. Available online: https: / CRAN.R-project.org/package=rgdal (accessed on 3 February 2021).

63. Gotelli, N.J.; Colwell, R.K. Quantifying biodiversity: Procedures and pitfalls in the measurement and comparison of species richness. Ecol. Lett. 2001, 4, 379-391. [CrossRef]

64. Jost, L. Entropy and diversity. Oikos 2006, 113, 363-375. [CrossRef]

65. Bates, A.J.; Lakeman Fraser, P.; Robinson, L.; Tweddle, J.C.; Sadler, J.P.; West, S.E.; Norman, S.; Batson, M.; Davies, L. The OPAL bugs count survey: Exploring the effects of urbanisation and habitat characteristics using citizen science. Urban Ecosyst. 2015, 18, 1477-1497. [CrossRef] 
66. Oksanen, J.; Blanchet, F.G.; Friendly, M.; Kindt, R.; Legendre, P.; McGlinn, D.; Minchin, P.R.; O’Hara, R.B.; Simspon, G.L.; Solymos, P.; et al. vegan: Community Ecology Package. R Package Version 2.5-4. 2019. Available online: https://CRAN.Rproject.org/package=vegan (accessed on 8 February 2021).

67. Kassambara, A. ggpubr: 'ggplot2' based Publication Ready Plots. R Package Version 0.4.0. 2020. Available online: https: / /CRAN.R-project.org/package=ggpubr (accessed on 22 January 2021).

68. Wickham, H. ggplot2: Elegant Graphics for Data Analysis; Springer: New York, NY, USA, 2016.

69. Pernat, N.; Kampen, H.; Jeschke, J.M.; Werner, D. Citizen science versus professional data collection: Comparison of approaches to mosquito monitoring in Germany. J. Appl. Ecol. 2021, 58, 214-223. [CrossRef]

70. Bertone, M.A.; Leong, M.; Bayless, K.M.; Malow, T.L.; Dunn, R.R.; Trautwein, M.D. Arthropods of the great indoors: Characterizing diversity inside urban and suburban homes. Peer] 2016, 4, e1582. [CrossRef]

71. Barberan, A.; Dunn, R.R.; Reich, B.J.; Pacifici, K.; Laber, E.B.; Menninger, H.L.; Morton, J.M.; Henley, J.B.; Leff, J.W.; Miller, S.L.; et al. The ecology of microscopic life in household dust. Proc. Biol. Sci. 2015, 282, 20151139. [CrossRef]

72. De Coster, G.; De Laet, J.; Vangestel, C.; Adriaensen, F.; Lens, L. Citizen science in action-Evidence for long-term, region-wide house sparrow declines in Flanders, Belgium. Landsc. Urban Plan. 2015, 134, 139-146. [CrossRef]

73. McMillan, J.R.; Armstrong, P.M.; Andreadis, T.G. Patterns of mosquito and arbovirus community composition and ecological indexes of arboviral risk in the northeast United States. PLoS Negl. Trop. Dis. 2020, 14, e0008066. [CrossRef]

74. Chaves, L.F.; Hamer, G.L.; Walker, E.D.; Brown, W.M.; Ruiz, M.O.; Kitron, U.D. Climatic variability and landscape heterogeneity impact urban mosquito diversity and vector abundance and infection. Ecosphere 2011, 2, 70. [CrossRef]

75. Ewing, D.A.; Cobbold, C.A.; Purse, B.V.; Nunn, M.A.; White, S.M. Modelling the effect of temperature on the seasonal population dynamics of temperate mosquitoes. J. Theor. Biol. 2016, 400, 65-79. [CrossRef] [PubMed]

76. Wilke, A.B.B.; Medeiros-Sousa, A.R.; Ceretti-Junior, W.; Marrelli, M.T. Mosquito populations dynamics associated with climate variations. Acta Trop. 2017, 166, 343-350. [CrossRef] [PubMed]

77. Roy, H.E.; Rorke, S.L.; Beckmann, B.; Booy, O.; Botham, M.S.; Brown, P.M.J.; Harrower, C.; Noble, D.; Sewell, J.; Walker, K. The contribution of volunteer recorders to our understanding of biological invasions. Biol. J. Linn. Soc. 2015, 115, 678-689. [CrossRef]

78. Vaux, A.G.C.; Medlock, J.M. Current status of invasive mosquito surveillance in the UK. Parasit. Vectors 2015, 8, 351. [CrossRef]

79. Callaghan, C.T.; Roberts, J.D.; Poore, A.G.B.; Alford, R.A.; Cogger, H.; Rowley, J.J.L. Citizen science data accurately predicts expert-derived species richness at a continental scale when sampling thresholds are met. Biodivers. Conserv. 2020, 29, 1323-1337. [CrossRef]

80. Soroye, P.; Ahmed, N.; Kerr, J.T. Opportunistic citizen science data transform understanding of species distributions, phenology, and diversity gradients for global change research. Glob. Chang. Biol. 2018, 24, 5281-5291. [CrossRef]

81. Fenoglio, M.S.; Rossetti, M.R.; Videla, M.; Baselga, A. Negative effects of urbanization on terrestrial arthropod communities: A meta-analysis. Glob. Ecol. Biogeogr. 2020, 29, 1412-1429. [CrossRef]

82. Pecoraro, H.L.; Day, H.L.; Reineke, R.; Stevens, N.; Withey, J.C.; Marzluff, J.M.; Meschke, J.S. Climatic and landscape correlates for potential West Nile virus mosquito vectors in the Seattle region. J. Vector Ecol. 2007, 32, 22-28. [CrossRef]

83. Wilke, A.B.B.; Caban-Martinez, A.J.; Ajelli, M.; Vasquez, C.; Petrie, W.; Beier, J.C. Mosquito adaptation to the extreme habitats of urban construction sites. Trends Parasitol. 2019, 35, 607-614. [CrossRef]

84. Früh, L.; Kampen, H.; Koban, M.B.; Pernat, N.; Schaub, G.A.; Werner, D. Oviposition of Aedes japonicus japonicus (Diptera: Culicidae) and associated native species in relation to season, temperature and land use in western Germany. Parasit. Vectors 2020, 13, 623. [CrossRef]

85. Medlock, J.M.; Vaux, A.G. Impacts of the creation, expansion and management of English wetlands on mosquito presence and abundance-developing strategies for future disease mitigation. Parasit. Vectors 2015, 8, 142. [CrossRef]

86. Zittra, C.; Vitecek, S.; Obwaller, A.G.; Rossiter, H.; Eigner, B.; Zechmeister, T.; Waringer, J.; Fuehrer, H.P. Landscape structure affects distribution of potential disease vectors (Diptera: Culicidae). Parasit. Vectors 2017, 10, 205. [CrossRef]

87. Vezzani, D. Artificial container-breeding mosquitoes and cemeteries: A perfect match. Trop. Med. Int. Health 2007, 12, 299-313. [CrossRef]

88. Rose, N.H.; Sylla, M.; Badolo, A.; Lutomiah, J.; Ayala, D.; Aribodor, O.B.; Ibe, N.; Akorli, J.; Otoo, S.; Mutebi, J.P.; et al. Climate and urbanization drive mosquito preference for humans. Curr. Biol. 2020, 30, 3570-3579. [CrossRef]

89. Dekoninck, W.; Hendrickx, F.; Vasn Bortel, W.; Versteirt, V.; Coosemans, M.; Damiens, D.; Hance, T.; De Clercq, E.M.; Hendrickx, G.; Schaffner, F.; et al. Human-induced expanded distribution of Anopheles plumbeus, experimental vector of West Nile virus and a potential vector of human malaria in Belgium. J. Med. Entomol. 2011, 48, 924-928. [CrossRef]

90. Schaffner, F.; Thiery, I.; Kaufmann, C.; Zettor, A.; Lengeler, C.; Mathis, A.; Bourgouin, C. Anopheles plumbeus (Diptera: Culicidae) in Europe: A mere nuisance mosquito or potential malaria vector? Malar. J. 2012, 11, 393. [CrossRef]

91. Dunn, R.R.; Beasley, D.E. Democratizing evolutionary biology, lessons from insects. Curr. Opin. Insect Sci. $2016,18,89-92$. [CrossRef] 